\title{
The role of EGFR-TKI for leptomeningeal metastases from non-small cell lung cancer
}

\author{
Xu Yufen ${ }^{1,2+}$, Song Binbin ${ }^{1,2+}$, Chen Wenyu ${ }^{1,2}$, Liu Jialiang ${ }^{1,2}$ and Yang Xinmei ${ }^{1,2^{*}}$
}

\begin{abstract}
Leptomeningeal metastasis (LM) is a terminal event in the development of non-small cell lung cancer (NSCLC). It has a poor prognosis with median survival of 1.9 months if untreated. The improvement of OS in NSCLC patients relatively increases incidence of $L M$. While current therapeutic options for $L M$ are limited. Epidermal growth factor receptortyrosine kinase inhibitors are a class of small molecules and show dramatic response in epidermal growth factor receptor mutated patients. It also has a distinct therapeutic potential against brain metastases. Although there are some studies on EGFR-TKIs and brain metastases, the role of EGFR-TKIs on LM are not fully clarified. In this review, we will summarize current evidences concerning the use and discuss the role of EGFR-TKIs on LM.
\end{abstract}

Keywords: Non-small cell lung cancer, Leptomeningeal metastasis, EGFR-TKIs

\section{Background}

Lung cancer is the most common cancer and leading cause of cancer deaths in the world (Ferlay et al. 2010). As improvement in treatment for non-small-cell lung carcinoma (NSCLC), previous rare complications become evident. Leptomeningeal metastasis (LM), namely cancer cells spreading to the meninges, is a terminal event in the development of NSCLC (Chamberlain 2005). LM occurs in $5 \%$ of cancers, and $14-29 \%$ of them derives from lung cancer (Grossman and Krabak 1999). LM has a poor prognosis with median survival of 1.9 months if untreated (Herrlinger et al. 2004). Intravenous chemotherapy is believed to have a limited role because its inability to form high drug concentrations in intracranial area due to blood brain barrier (BBB). Current available drugs for intrathecal chemotherapy (ITC) including methotrexate and cytarabine have limited antitumor activity in lung cancer (Oechsle et al. 2010). Although whole brain radiotherapy (WBRT) is an effective therapy for brain parenchyma metastasis, it does

\footnotetext{
*Correspondence: yangxinmei128@sina.com

${ }^{+} X u$ Yufen and Song Binbin contributed equally to this work

${ }^{2}$ Department of Oncology, The First Affiliated Hospital of Jiaxing

University, No. 1882, Zhonghuan South Road, Jiaxing 314000, Zhejiang,

People's Republic of China

Full list of author information is available at the end of the article
}

not exhibit survival benefit on LM (Morris et al. 2012). Epidermal growth factor receptor-tyrosine kinase inhibitors (EGFR-TKIs) are a class of small molecules and have demonstrated dramatic response rates from 60 to $90 \%$ in sensitizing EGFR mutation NSCLC population as systemic therapy (Maemondo et al. 2010; Mitsudomi et al. 2010; Mok et al. 2009). EGFR-TKIs also showed a distinct therapeutic potential against brain metastases of NSCLC (Namba et al. 2004; Hotta et al. 2004), suggesting its ability to penetrate BBB into cerebrospinal fluid (CSF). In addition, EGFR-TKIs have antitumor efficacy in central nervous system metastases even for those patients with extracranial lesions failure after standard dose EGFR-TKIs treatment (Grommes et al. 2011; Jackman et al. 2006; Dhruva and Socinski 2009; Clarke et al. 2010; Kuiper and Smit 2013; Hata et al. 2011; Kawamura et al. 2015). Notwithstanding there are some studies on EGFR-TKIs and brain metastases, the role of EGFR-TKIs on LM are not fully clarified. In this review, we will summarize current evidences concerning the use and discuss the role of EGFR-TKIs on LM.

\section{Definition and diagnosis of LM}

LM is defined as the spread of malignant cells to the leptomeninges and subarachnoid space and dissemination of tumors cells with the CSF compartment (Gleissner 
and Chamberlain 2006). Symptoms of LM contains mental changes, headaches, seizures, and back pain, etc. However, it can also exhibit some abscopal symptoms. Sim et al. reported a case chest wall pain as the presenting symptom of LM (Sim et al. 2014). The gold standard of diagnosis with LM is detection of malignant cells in CSF (Chamberlain 2005). While CSF examination can only perform in part of patients. Therefore, the finding of meningeal enhancement in cranial and/or spinal MRI combine with neurological symptoms are also recognized as LM.

\section{Current therapeutic modalities of EGFR-TKIs for LM}

EGFR-TKIs open up era of target therapy on NSCLC and markedly prolong OS and PFS on EGFR $\mathrm{MT}_{\mathrm{MT}}$ patients. The improvement of OS in NSCLC patients relatively increases incidence of LM. In the following part, we will focus on therapeutic options of EGFR-TKIs on LM. Table 1 summaries current clinical trials on application EGFR-TKIs for LM.

\section{EGFR mutation versus wild type}

EGFR mutation type (EGFR $\left.{ }_{M T}\right)$ NSCLC is an important subgroup of NSCLC, accounting for about $50 \%$ in Asian and $10 \%$ in Caucasian population (Hirsch and Bunn 2009). Mounting evidences have shown EGFR-TKIs improved overall response rate (ORR), progression-free survival (PFS) and/or overall survival (OS) with minimal toxicities in EGFR sensitive mutation patients (Maemondo et al. 2010; Mitsudomi et al. 2010; Rosell et al. 2012; Sequist et al. 2013; Zhou et al. 2011). In the case of LM, EGFR $\mathrm{MT}_{\mathrm{MT}}$ type also contributed to longer OS and PFS as well as better performance status (PS). A retrospective study conducted by Umemura et al. showed the median survival time (MST) for all NSCLC patients with LM was 3.6 months, while MST in exon 19 deletion, exon 21 mutation, and wild type patients were 11.0, 7.1, and 1.4 months. Similar results were seen in PFS. The median time to progression (mTTP) for these three group were 7.8, 2.0, and 0.9 months (Umemura et al. 2012). Although EGFR-TKIs have an initial good response, it inevitably moves toward resistance around 1-year (Maemondo et al. 2010; Mitsudomi et al. 2010; Mok et al. 2009). Several mechanisms lead to EGFR-TKIs resistance, including secondary mutation (Primary T790M mutation), c-Met amplification, and transformation to small cell lung cancer (Kobayashi et al. 2005). T790M mutation is an important mechanism of acquired resistance, and there are about $50 \%$ T790M mutation in patients after TKI failure (Sequist et al. 2011; Oxnard et al. 2011; Chen et al. 2009; Balak et al. 2006). Most of LM occurs at late course of NSCLC, patients usually have acquire resistance of EGFR-TKIs. However, intracranial metastases retain sensitive mutation even when extracranial lesions develop secondary mutation such as T790M (Jackman et al. 2006; Clarke et al. 2010; Balak et al. 2006; Heon et al. 2010). Lack of selection pressure as poor penetration of TKIs in intracranial metastases might explain this phenomenon.

First, second, and third-generation EGFR-TKIs

As first-generation EGFR-TKIs, erlotinib (Tarceva) and gefitinib (Iressa) exhibit dramatic efficacy in selected NSCLC patients. Each of them has evidence proving their efficacy as first-line, second-line, third-line, or maintenance therapy (Mok et al. 2009; Qi et al. 2012; Alimujiang et al. 2013). Certainly, there are some studies comparing efficacy and toxicity between erlotinib and gefitinib. Burotto et al. found both of them had similar toxicity profiles as well as outcomes including ORR, PFS, and OS (Burotto et al. 2015). However, Wu et al. conducted a study enrolled 716 patients, and found different effectiveness between gefitinib and erlotinib for NSCLC $_{\mathrm{MT}}$ patients (Wu et al. 2011). In addition, several studies showed erlotinib produced clinical benefits in some patients after gefitinib failure (Hata et al. 2011; Kaira et al. 2010). Similar phenomenon was seen in LM. Several studies reported erlotinib had a good response for LM after gefitinib failure (Yang et al. 2015; Yuan et al. 2012; Masuda et al. 2011; Katayama et al. 2009). Erlotinib was believed to have more penetration rate into the CSF than gefitinib. Togashi et al. compared CSF concentration and penetration rate between gefitinib and erlotinib in 15 patients (Togashi et al. 2012). The results showed the CSF concentration for gefitinib and erlotinib were $8.2 \pm 4.3 \mathrm{nM}$ and $66.9 \pm 39.0 \mathrm{nM}$, respectively. The penetration rate were $1.13 \pm 0.36$ and $2.77 \pm 0.45 \%$, respectively. Patients with erlotinib also achieved a preferentially higher intracranial response rate than those with gefitinib (4/7 vs. $1 / 3$ ). Another study retrospectively analyzed the two EGFR-TKIs efficacy on 25 NSCLC patients with LM (Lee et al. 2013). They found patients with erlotinib showed better cytological conversion rate of LM than those with gefitinib (9/14 vs. 1/11). In addition, another first-generation EGFR-TKI icotinib also showed efficacy on LM from NSCLC with EGFR mutation (Gong et al. 2015). Of course, second-generation (Afatinib) and third-generation TKIs (AZD9291) have been applied in clinical practice or clinical trials. LuxLung 3 and Lux-Lung 6 showed first-line afatinib significantly prolonged PFS compared to platinum-based chemotherapy (Sequist et al. 2013; Wu et al. 2014). Pooled analysis of Lux-Lung 3 and Lux-Lung 6 showed afatinib improved OS in patients with del19 EGFR mutations but not Leu858Arg EGFR mutations, indicating the potential mechanistic differences between afatinib 


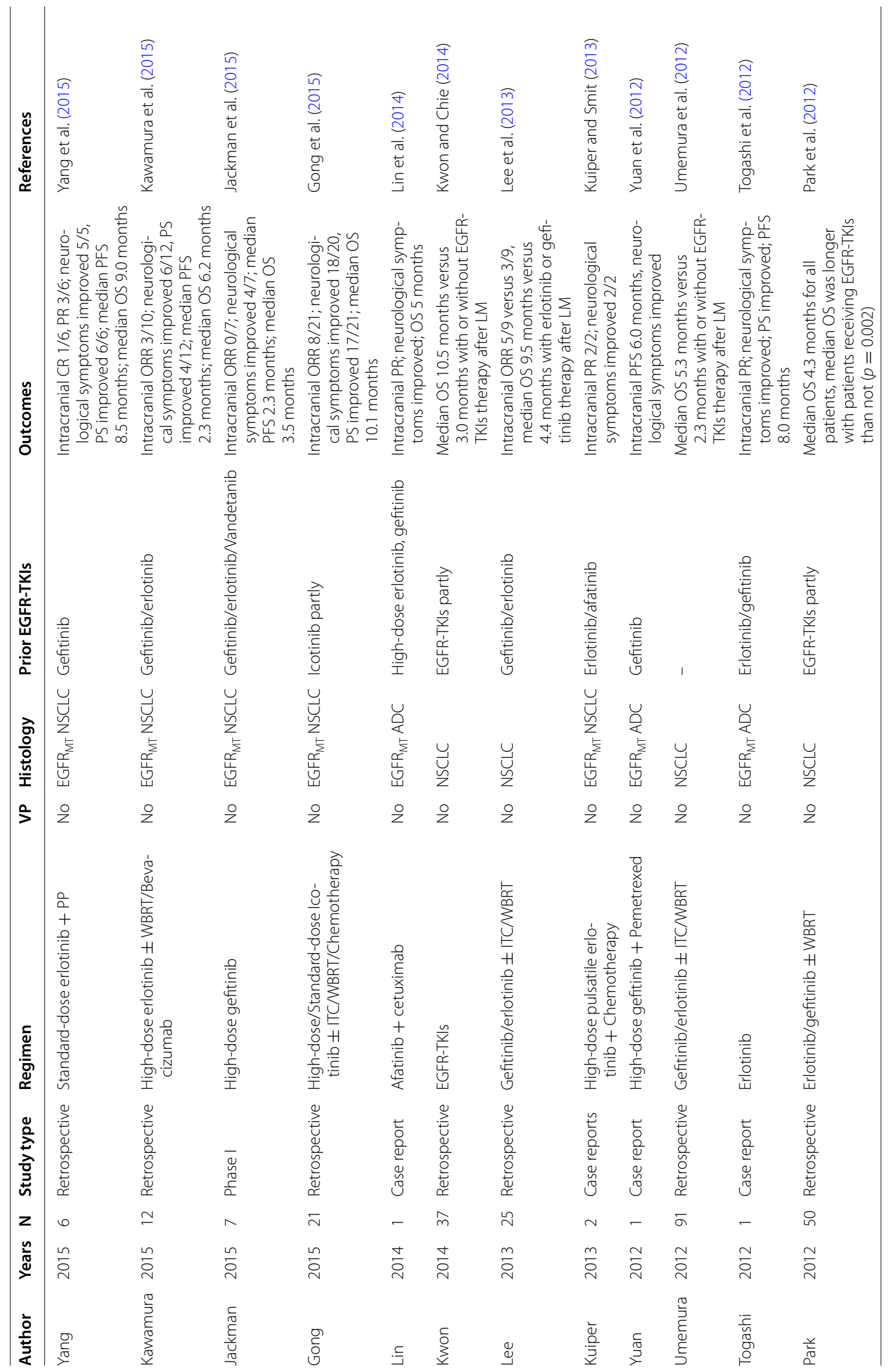




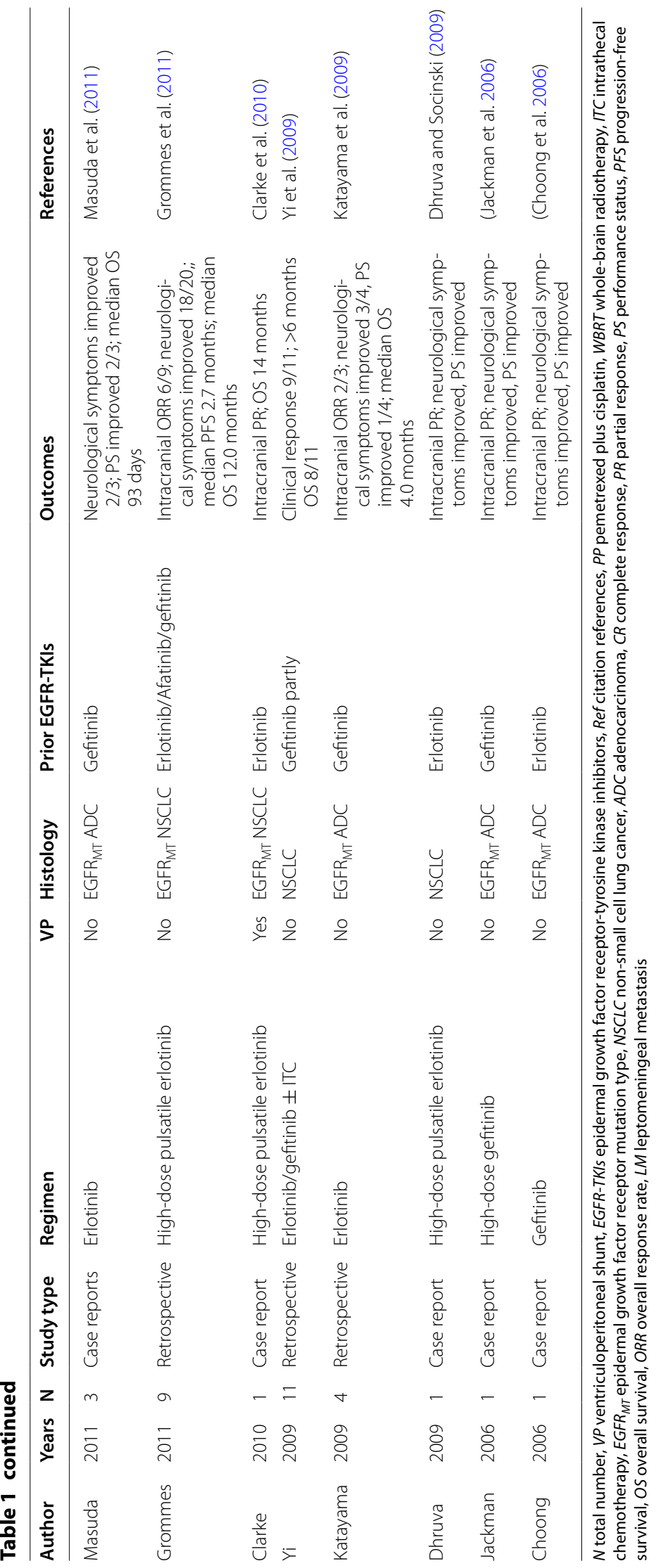


and first-generation EGFR-TKIs (Yang et al. 2015). Recent two studies Lux-Lung 7 and Lux-Lung 8 compared afatinib with gefitinib and erlotinib showing superiority of afatinib in PFS and OS (Park et al. 2016; Soria et al. 2015). Lin et al. reported a case afatinib combination with cetuximab was effective for LM after erlotinib/ gefitinib failure (Lin et al. 2014). Another report on outcomes of pretreated NSCLC patients with CNS metastasis who received afatinib showed that thirty-five percent (11 of 31) of evaluable patients had a cerebral response (Hoffknecht et al. 2015). CSF data from one patient showed afatinib CSF concentration of approximately $1.0 \mathrm{nM}$. Afatinib appears to penetrate into the CNS with concentrations high enough to have clinical effect on CNS metastases. Osimertinib (AZD9291) is a third-generation EGFR-TKI. BLOOM study showed osimertinib demonstrated encouraging preliminary activity in heavily pretreated patients with LM disease from EGFR ${ }^{\mathrm{MT}}$ NSCLC (Yang 2016). Ahn et al. analyzed patients with brain metastasis from AURA and AURA2 studies and showed osimertinib achieved an ORR of $56 \%$ (Ahn et al. 2015). CSF data from one patient showed AZD9291 CSF concentration of $3.44 \mathrm{nM}$. Nanjo et al. established an in vivo LM mice model and found osimertinib markedly inhibited progression of LM even after refractory to erlotinib (Nanjo et al. 2016).

\section{High-dose versus standard dose EGFR-TKIs}

Traditional chemotherapy is unable to penetrate into CSF due to BBB. This causes limited efficacy of systemic therapy on intracranial lesions. EGFR-TKIs are a class of small molecular agents and supposed to easily penetrate into the CSF, however, the penetration rate is still low. Therefore, intracranial failure of EGFR-TKIs is consider as pharmacokinetic failure. Higher dose EGFRTKIs is supposed to correlate with higher concentrations in the CSF. Togashi et al. studied the relationship between plasma and CSF concentrations of erlotinib (Togashi et al. 2011). The authors found the plasma erlotinib concentrations at a dose of 75 and $150 \mathrm{mg}$ were 433 and $1117 \mathrm{nM}$, corresponding to CSF concentrations 14 and $44 \mathrm{nM}$. There was a good correlation between plasma and CSF concentrations $\left(\mathrm{R}^{2}=0.84, p<0.001\right)$. For that matter, a series studies have evaluated the efficacy of high-dose EGFR-TKIs on intracranial metastases from NSCLC. Kawamura et al. analyzed safety and efficacy of 35 patients with or without high-dose erlotinib and found high-dose erlotinib significantly improved PS and neurological symptoms with no elevated rates of severe adverse events (AEs) as compared to standarddose EGFR-TKIs (Kawamura et al. 2015). Median OS in high-dose erlotinib and standard-dose EGFR-TKIs were 6.2 and 5.9 months, respectively (Kawamura et al. 2015).
Jackman et al. conducted a phase I study of high-dose gefitinib on LM from NSCLC and found high-dose gefitinib could improve neurological symptoms with minor toxicity (Jackman et al. 2015). Several studies reported high-dose EGFR-TKIs improved neurological symptoms and decreased intracranial metastases after standarddose EGFR-TKIs failure (Dhruva and Socinski 2009; Clarke et al. 2010; Kuiper and Smit 2013; Hata et al. 2011; Yuan et al. 2012).

\section{Combination with WBRT}

WBRT has an important role in brain metastases, while its impact on LM is unknown. A study of Morris et al. showed WBRT might play a role in symptom control, but it did not improve OS of LM patients (Morris et al. 2012). Although WBRT alone does not exhibit superior outcomes, combination with EGFR-TKIs seems to be effective. In Yang's study, four patients achieve partial or complete response who received WBRT, while the other two patients achieve stable disease who did not combine with WBRT (Yang et al. 2015). Of course, the sample size is small, further study are needed to evaluate WBRT combination with EGFR-TKIs.

\section{Conclusion}

LM is a terminal event of NSCLC and its prognosis is extremely poor. Current therapeutic options for LM are limited. EGFR-TKIs as important target drugs exhibit good efficacy for EGFR $\mathrm{MT}_{\mathrm{MT}}$ patients with LM. In this review, we discuss selection and therapeutic strategy of EGFR-TKIs for LM. EGFR ${ }_{M T}$ patients with LM might be more appropriate for EGFR-TKIs therapy than those EGFR wild type patients. It seems erlotinib and highdose regimen could benefit more patients. Also combination with WBRT is another option. Nevertheless, current evidence are derived from respective and case reports study, further randomized control trials are needed to fully understand the role of EGFR-TKIs for LM.

\section{Abbreviations}

ADC: adenocarcinoma; AEs: adverse events; BBB: blood brain barrier; CR: complete response; CSF: cerebrospinal fluid; EGFR: epidermal growth factor receptor; EGFRMT: EGFR mutation type; ITC: intrathecal chemotherapy; LM: leptomeningeal metastasis; MST: median survival time; MTTP: median time to progression; NSCLC: non-small cell lung cancer; ORR: overall response rate; OS: overall survival; PFS: progression-free survival; PR: partial response; PS: performance score; TKI: tyrosine kinase inhibitor; VP: ventriculoperitoneal shunt; WBRT: whole brain radiotherapy.

\section{Authors' contributions}

$X Y$ and SB wrote this manuscript and acquitted data, CW and $L J$ helped search literatures, YX made substantial contributions to conception and interpretation of data. All authors read and approved the final manuscript.

\section{Author details}

1 School of Medicine, Jiaxing University, Jiaxing 314000, Zhejiang, People's Republic of China. ${ }^{2}$ Department of Oncology, The First Affiliated Hospital 
of Jiaxing University, No. 1882, Zhonghuan South Road, Jiaxing 314000, Zhejiang, People's Republic of China.

\section{Acknowledgements}

This study was supported by grants from Development Center for Medical Science and Technology National Health Commission of the People's Republic of China (W2012FZ120), Key Disciplines of Jiaxing (Oncology)(04-F-14), Science and Technology Projects of Jiaxing (2014AY21030-4) and Innovation team of Lung Cancer in Early Diagnosis and Comprehensive Treatment (2014). The funders had no role in study design, data collection and analysis, decision to publish, or preparation of the manuscript.

\section{Competing interests}

The authors declare that they have no competing interests.

Received: 2 November 2015 Accepted: 19 July 2016

Published online: 03 August 2016

\section{References}

Ahn M, Tsai C, Yang J, Shepherd F, Satouchi M, Kim D et al (2015) 3083 AZD9291 activity in patients with EGFR-mutant advanced non-small cell lung cancer (NSCLC) and brain metastases: Data from Phase II studies. Eur J Cancer 51:S625-S626

Alimujiang S, Zhang T, Han ZG, Yuan SF, Wang Q, Yu TT et al (2013) Epidermal growth factor receptor tyrosine kinase inhibitor versus placebo as maintenance therapy for advanced non- small-cell lung cancer: a meta-analysis of randomized controlled trials. Asian Pac J Cancer Prev 14(4):2413-2419

Balak MN, Gong Y, Riely GJ, Somwar R, Li AR, Zakowski MF et al (2006) Novel D761Y and common secondary T790 M mutations in epidermal growth factor receptor-mutant lung adenocarcinomas with acquired resistance to kinase inhibitors. Clin Cancer Res 12(21):6494-6501. doi:10.1158/10780432.ccr-06-1570

Burotto M, Manasanch EE, Wilkerson J, Fojo T (2015) Gefitinib and erlotinib in metastatic non-small cell lung cancer: a meta-analysis of toxicity and efficacy of randomized clinical trials. Oncologist 20(4):400-410. doi:10.1634/ theoncologist.2014-0154

Chamberlain MC (2005) Neoplastic meningitis. J Clin Oncol 23(15):3605-3613. doi:10.1200/jco.2005.01.131

Chen HJ, Mok TS, Chen ZH, Guo AL, Zhang XC, Su J et al (2009) Clinicopathologic and molecular features of epidermal growth factor receptor T790 M mutation and c-MET amplification in tyrosine kinase inhibitor-resistant Chinese non-small cell lung cancer. Pathol Oncol Res 15(4):651-658. doi:10.1007/s12253-009-9167-8

Choong NW, Dietrich S, Seiwert TY, Tretiakova MS, Nallasura V, Davies GC et al. (2006) Gefitinib response of erlotinib-refractory lung cancer involving meninges-role of EGFR mutation. Nat Clin Pract Oncol 3(1):50-57; quiz 1 p following 7. doi:10.1038/ncponc0400

Clarke JL, Pao W, Wu N, Miller VA, Lassman AB (2010) High dose weekly erlotinib achieves therapeutic concentrations in CSF and is effective in leptomeningeal metastases from epidermal growth factor receptor mutant lung cancer. J Neurooncol 99(2):283-286. doi:10.1007/s11060-010-0128-6

Dhruva N, Socinski MA (2009) Carcinomatous meningitis in non-small-cell lung cancer: response to high-dose erlotinib. J Clin Oncol 27(22):e31e32. doi:10.1200/jco.2008.21.0963

Ferlay J, Shin HR, Bray F, Forman D, Mathers C, Parkin DM (2010) Estimates of worldwide burden of cancer in 2008: GLOBOCAN 2008. Int J Cancer 127(12):2893-2917

Gleissner B, Chamberlain MC (2006) Neoplastic meningitis. Lancet Neurol 5(5):443-452. doi:10.1016/s1474-4422(06)70443-4

Gong L, Xiong M, Huang Z, Miao L, Fan Y (2015) Icotinib might be effective for the treatment of leptomeningeal carcinomatosis in non-small cell lung cancer with sensitive EGFR mutations. Lung Cancer. doi:10.1016/j. lungcan.2015.06.001

Grommes C, Oxnard GR, Kris MG, Miller VA, Pao W, Holodny Al et al (2011) “Pulsatile" high-dose weekly erlotinib for CNS metastases from EGFR mutant non-small cell lung cancer. Neuro Oncol 13(12):1364-1369. doi:10.1093/ neuonc/nor12
Grossman SA, Krabak MJ (1999) Leptomeningeal carcinomatosis. Cancer Treat Rev 25(2):103-119. doi:10.1053/ctrv.1999.0119

Hata A, Kaji R, Fujita S, Katakami N (2011a) High-dose erlotinib for refractory brain metastases in a patient with relapsed non-small cell lung cancer. J Thorac Oncol 6(3):653-654. doi:10.1097/JTO.0b013e3181d899bb

Hata A, Katakami N, Yoshioka H, Fujita S, Kunimasa K, Nanjo S et al (2011b) Erlotinib after gefitinib failure in relapsed non-small cell lung cancer: clinical benefit with optimal patient selection. Lung Cancer 74(2):268-273. doi:10.1016/j.lungcan.2011.03.010

Heon S, Yeap BY, Britt GJ, Costa DB, Rabin MS, Jackman DM et al (2010) Development of central nervous system metastases in patients with advanced non-small cell lung cancer and somatic EGFR mutations treated with gefitinib or erlotinib. Clin Cancer Res 16(23):5873-5882. doi:10.1158/1078-0432.ccr-10-1588

Herrlinger U, Forschler H, Kuker W, Meyermann R, Bamberg M, Dichgans J et al (2004) Leptomeningeal metastasis: survival and prognostic factors in 155 patients. J Neurol Sci 223(2):167-178. doi:10.1016/j.jns.2004.05.008

Hirsch FR, Bunn PA Jr (2009) EGFR testing in lung cancer is ready for prime time. Lancet Oncol 10(5):432-433. doi:10.1016/s1470-2045(09)70110-x

Hoffknecht P, Tufman A, Wehler T, Pelzer T, Wiewrodt R, Schutz M et al (2015) Efficacy of the irreversible ErbB family blocker afatinib in epidermal growth factor receptor (EGFR) tyrosine kinase inhibitor (TKI)-pretreated non-small-cell lung cancer patients with brain metastases or leptomeningeal disease. J Thorac Oncol 10(1):156-163. doi:10.1097/ ito.0000000000000380

Hotta K, Kiura K, Ueoka H, Tabata M, Fujiwara K, Kozuki T et al (2004) Effect of gefitinib ('Iressa', ZD1839) on brain metastases in patients with advanced non-small-cell lung cancer. Lung Cancer 46(2):255-261. doi:10.1016/j. lungcan.2004.04.036

Jackman DM, Holmes AJ, Lindeman N, Wen PY, Kesari S, Borras AM et al (2006) Response and resistance in a non-small-cell lung cancer patient with an epidermal growth factor receptor mutation and leptomeningeal metastases treated with high-dose gefitinib. J Clin Oncol 24(27):4517-4520. doi:10.1200/jco.2006.06.6126

Jackman DM, Cioffredi LA, Jacobs L, Sharmeen F, Morse LK, Lucca J et al (2015) A phase I trial of high dose gefitinib for patients with leptomeningeal metastases from non-small cell lung cancer. Oncotarget 6(6):4527-4536

Kaira K, Naito T, Takahashi T, Ayabe E, Shimoyama R, Kaira R et al (2010) Pooled analysis of the reports of erlotinib after failure of gefitinib for non-small cell lung cancer. Lung Cancer 68(1):99-104. doi:10.1016/j. lungcan.2009.05.006

Katayama T, Shimizu J, Suda K, Onozato R, Fukui T, Ito S et al (2009) Efficacy of erlotinib for brain and leptomeningeal metastases in patients with lung adenocarcinoma who showed initial good response to gefitinib. J Thorac Oncol 4(11):1415-1419. doi:10.1097/JTO.0b013e3181b62572

Kawamura T, Hata A, Takeshita J, Fujita S, Hayashi M, Tomii Ket al (2015) Highdose erlotinib for refractory leptomeningeal metastases after failure of standard-dose EGFR-TKIs. Cancer Chemother Pharmacol 75(6):1261-1266. doi:10.1007/s00280-015-2759-y

Kobayashi S, Boggon TJ, Dayaram T, Janne PA, Kocher O, Meyerson M et al (2005) EGFR mutation and resistance of non-small-cell lung cancer to gefitinib. N Engl J Med 352(8):786-792. doi:10.1056/NEJMoa044238

Kuiper JL, Smit EF (2013) High-dose, pulsatile erlotinib in two NSCLC patients with leptomeningeal metastases-one with a remarkable thoracic response as well. Lung Cancer 80(1):102-105. doi:10.1016/j. lungcan.2012.12.024

Kwon J, Chie EK (2014) Impact of multimodality approach for patients with leptomeningeal metastases from solid tumors. J Korean Med Sci 29(8):1094-1101. doi:10.3346/jkms.2014.29.8.1094

Lee E, Keam B, Kim DW, Kim TM, Lee SH, Chung DH et al (2013) Erlotinib versus gefitinib for control of leptomeningeal carcinomatosis in nonsmall-cell lung cancer. J Thorac Oncol 8(8):1069-1074. doi:10.1097/ JTO.0b013e318294c8e8

Lin CH, Lin MT, Kuo YW, Ho CC (2014) Afatinib combined with cetuximab for lung adenocarcinoma with leptomeningeal carcinomatosis. Lung Cancer 85(3):479-480. doi:10.1016/j.lungcan.2014.06.002

Maemondo M, Inoue A, Kobayashi K, Sugawara S, Oizumi S, Isobe H et al (2010) Gefitinib or chemotherapy for non-small-cell lung cancer with mutated EGFR. N Engl J Med 362(25):2380-2388. doi:10.1056/ NEJMoa0909530 
Masuda T, Hattori N, Hamada A, Iwamoto H, Ohshimo S, Kanehara M et al (2011) Erlotinib efficacy and cerebrospinal fluid concentration in patients with lung adenocarcinoma developing leptomeningeal metastases during gefitinib therapy. Cancer Chemother Pharmacol 67(6):1465-1469. doi:10.1007/s00280-011-1555-6

Mitsudomi T, Morita S, Yatabe Y, Negoro S, Okamoto I, Tsurutani J et al (2010) Gefitinib versus cisplatin plus docetaxel in patients with non-small-cell lung cancer harbouring mutations of the epidermal growth factor receptor (WJTOG3405): an open label, randomised phase 3 trial. Lancet Oncol 11(2):121-128. doi:10.1016/s1470-2045(09)70364-X

Mok TS, Wu YL, Thongprasert S, Yang CH, Chu DT, Saijo N et al (2009) Gefitinib or carboplatin-paclitaxel in pulmonary adenocarcinoma. N Engl J Med 361(10):947-957. doi:10.1056/NEJMoa0810699

Morris PG, Reiner AS, Szenberg OR, Clarke JL, Panageas KS, Perez HR et al (2012) Leptomeningeal metastasis from non-small cell lung cancer: survival and the impact of whole brain radiotherapy. J Thorac Oncol 7(2):382-385. doi:10.1097/JTO.0b013e3182398e4f

Namba Y, Kijima T, Yokota S, Niinaka M, Kawamura S, Iwasaki T et al (2004) Gefitinib in patients with brain metastases from non-small-cell lung cancer: review of 15 clinical cases. Clin Lung Cancer 6(2):123-128. doi:10.3816/ CLC.2004.n.026

Nanjo S, Ebi H, Arai S, Takeuchi S, Yamada T, Mochizuki S et al (2016) High efficacy of third generation EGFR inhibitor AZD9291 in a leptomeningeal carcinomatosis model with EGFR-mutant lung cancer cells. Oncotarget 7(4):3847-3856. doi:10.18632/oncotarget.6758

Oechsle K, Lange-Brock V, Kruell A, Bokemeyer C, de Wit M (2010) Prognostic factors and treatment options in patients with leptomeningeal metastases of different primary tumors: a retrospective analysis. J Cancer Res Clin Oncol 136(11):1729-1735. doi:10.1007/s00432-010-0831-x

Oxnard GR, Arcila ME, Sima CS, Riely GJ, Chmielecki J, Kris MG et al (2011) Acquired resistance to EGFR tyrosine kinase inhibitors in EGFR-mutant lung cancer: distinct natural history of patients with tumors harboring the T790M mutation. Clin Cancer Res 17(6):1616-1622. doi:10.1158/10780432.ccr-10-2692

Park JH, Kim YJ, Lee JO, Lee KW, Kim JH, Bang SM et al (2012) Clinical outcomes of leptomeningeal metastasis in patients with non-small cell lung cancer in the modern chemotherapy era. Lung Cancer 76(3):387-392. doi:10.1016/j.lungcan.2011.11.022

Park K, Tan EH, O'Byrne K, Zhang L, Boyer M, Mok T et al (2016) Afatinib versus gefitinib as first-line treatment of patients with EGFR mutation-positive non-small-cell lung cancer (LUX-Lung 7): a phase 2B, open-label, randomised controlled trial. Lancet Oncol 17(5):577-589. doi:10.1016/ s1470-2045(16)30033-X

Qi WX, Shen Z, Lin F, Sun YJ, Min DL, Tang LN et al (2012) Comparison of the efficacy and safety of EFGR tyrosine kinase inhibitor monotherapy with standard second-line chemotherapy in previously treated advanced nonsmall-cell lung cancer: a systematic review and meta-analysis. Asian Pac J Cancer Prev 13(10):5177-5182

Rosell R, Carcereny E, Gervais R, Vergnenegre A, Massuti B, Felip E et al (2012) Erlotinib versus standard chemotherapy as first-line treatment for European patients with advanced EGFR mutation-positive non-small-cell lung cancer (EURTAC): a multicentre, open-label, randomised phase 3 trial. Lancet Oncol 13(3):239-246. doi:10.1016/s1470-2045(11)70393-x

Sequist LV, Waltman BA, Dias-Santagata D, Digumarthy S, Turke AB, Fidias P et al. (2011) Genotypic and histological evolution of lung cancers acquiring resistance to EGFR inhibitors. Sci Transl Med 3(75):75ra26. doi:10.1126/ scitransImed.3002003

Sequist LV, Yang JC, Yamamoto N, O'Byrne K, Hirsh V, Mok T et al (2013) Phase III study of afatinib or cisplatin plus pemetrexed in patients with metastatic lung adenocarcinoma with EGFR mutations. J Clin Oncol 31(27):33273334. doi:10.1200/jco.2012.44.2806

Sim KB, Nam KY, Lee HJ, Park JW, Ryu GH, Chang J et al (2014) Chest wall pain as the presenting symptom of leptomeningeal carcinomatosis. Ann Rehabil Med 38(6):861-864. doi:10.5535/arm.2014.38.6.861
Soria JC, Felip E, Cobo M, Lu S, Syrigos K, Lee KH et al (2015) Afatinib versus erlotinib as second-line treatment of patients with advanced squamous cell carcinoma of the lung (LUX-Lung 8): an open-label randomised controlled phase 3 trial. Lancet Oncol 16(8):897-907. doi:10.1016/ s1470-2045(15)00006-6

Togashi Y, Masago K, Fukudo M, Tsuchido Y, Okuda C, Kim YH et al (2011) Efficacy of increased-dose erlotinib for central nervous system metastases in non-small cell lung cancer patients with epidermal growth factor receptor mutation. Cancer Chemother Pharmacol 68(4):1089-1092. doi:10.1007/s00280-011-1691-z

Togashi Y, Masago K, Hamatani Y, Sakamori Y, Nagai H, Kim YH et al (2012a) Successful erlotinib rechallenge for leptomeningeal metastases of lung adenocarcinoma after erlotinib-induced interstitial lung disease: a case report and review of the literature. Lung Cancer 77(2):464-468. doi:10.1016/j.lungcan.2012.04.013

Togashi Y, Masago K, Masuda S, Mizuno T, Fukudo M, Ikemi Y et al (2012b) Cerebrospinal fluid concentration of gefitinib and erlotinib in patients with non-small cell lung cancer. Cancer Chemother Pharmacol 70(3):399-405. doi:10.1007/s00280-012-1929-4

Umemura S, Tsubouchi K, Yoshioka H, Hotta K, Takigawa N, Fujiwara K et al (2012) Clinical outcome in patients with leptomeningeal metastasis from non-small cell lung cancer: Okayama Lung Cancer Study Group. Lung Cancer 77(1):134-139. doi:10.1016/j.lungcan.2012.03.002

Wu JY, Wu SG, Yang CH, Chang YL, Chang YC, Hsu YC et al (2011) Comparison of gefitinib and erlotinib in advanced NSCLC and the effect of EGFR mutations. Lung Cancer 72(2):205-212. doi:10.1016/j.lungcan.2010.08.013

Wu YL, Zhou C, Hu CP, Feng J, Lu S, Huang Y et al (2014) Afatinib versus cisplatin plus gemcitabine for first-line treatment of Asian patients with advanced non-small-cell lung cancer harbouring EGFR mutations (LUX-Lung 6): an open-label, randomised phase 3 trial. Lancet Oncol 15(2):213-222. doi:10.1016/s1470-2045(13)70604-1

Yang J (ed) (2016) Osimertinib activity in patients (pts) with leptomeningeal (LM) disease from non-small cell lung cancer (NSCLC): updated results from BLOOM, a Phase I study. Abstract 9002 [Oral Presentation]. Annual meeting of the ASCO

Yang H, Yang X, Zhang Y, Liu X, Deng Q, Zhao M et al (2015a) Erlotinib in combination with pemetrexed/cisplatin for leptomeningeal metastases and cerebrospinal fluid drug concentrations in lung adenocarcinoma patients after gefitinib faliure. Target Oncol 10(1):135-140. doi:10.1007/ s11523-014-0326-9

Yang JC, Wu YL, Schuler M, Sebastian M, Popat S, Yamamoto N et al (2015b) Afatinib versus cisplatin-based chemotherapy for EGFR mutationpositive lung adenocarcinoma (LUX-Lung 3 and LUX-Lung 6): analysis of overall survival data from two randomised, phase 3 trials. Lancet Oncol 16(2):141-151. doi:10.1016/s1470-2045(14)71173-8

Yi HG, Kim HJ, Kim YJ, Han SW, Oh DY, Lee SH et al (2009) Epidermal growth factor receptor (EGFR) tyrosine kinase inhibitors (TKIs) are effective for leptomeningeal metastasis from non-small cell lung cancer patients with sensitive EGFR mutation or other predictive factors of good response for EGFR TKI. Lung Cancer 65(1):80-84. doi:10.1016/j.lungcan.2008.10.016

Yuan Y, Tan C, Li M, Shen H, Fang X, Hu Y et al (2012) Activity of pemetrexed and high-dose gefitinib in an EGFR-mutated lung adenocarcinoma with brain and leptomeningeal metastasis after response to gefitinib. World J Surg Oncol 10:235. doi:10.1186/1477-7819-10-235

Zhou C, Wu YL, Chen G, Feng J, Liu XQ, Wang C et al (2011) Erlotinib versus chemotherapy as first-line treatment for patients with advanced EGFR mutation-positive non-small-cell lung cancer (OPTIMAL, CTONG-0802): a multicentre, open-label, randomised, phase 3 study. Lancet Oncol 12(8):735-742. doi:10.1016/s1470-2045(11)70184-x 